\title{
POLÍTICA DOCENTE, ESCOLA PÚBLICA BRASILEIRA E O PROJETO \\ CAPITALISTA.
}

\author{
SUSANA SCHNEID SCHERER ${ }^{1}$
}

\section{INTRODUÇÃO}

Trata-se do esboço inicial para composição de objeto de pesquisa, que tem como propósito investigar desdobramentos das políticas escolares sobre o trabalho do professor no chão-escolar, especialmente, enfocando parâmetros de democratização educacional e social.

O objetivo central é investigar a política docente no bojo em que esta acontece. Assim temos sido inclinados, a partir dos apontamentos de Harvey (2013) e Meszáros (2013), aos efeitos do seio de crise dos lucros capitais, apresentando um grupo de estratégias para recomposição de sua hegemonia na tríade reestruturação produtiva, globalização e neoliberalização, que influem diretamente na forma do Estado e de suas políticas, o que elevam extensões da escola aos docentes anseios societários mercantis que se tornam primazias em relação a princípios sociais democráticos.

\section{METODOLOGIA}

Como suporte metodológico temos utilizado a proposta de Ball (2009), no Brasil legitimada por Mainardes (2006) pelas suscitações que apontam para investigar as políticas educativas desde o "chão-escolar" e valorando o papel do professor neste passo.

Ball (2009) considera uma política um processo vivo que é construído por sujeitos ativos. Assim, para ele uma política é quase como a atuação em uma peça teatral, onde se têm as palavras de um texto e que

\footnotetext{
${ }^{1}$ Doutoranda em Educação pela Universidade Federal de Pelotas, UFPEL. E-mail: susana_scherer@hotmail.com.
} 
precisam ser transformadas em ação. Os professores têm o papel dos atores principais, sendo os protagonistas da concretização desta peça.

Esta compreensão guarda ainda relações com a concepção da política educacional como discurso. O que diz respeito a uma não linearidade, harmonia ou neutralidade. Um campo de disputa que é produto e produtor de orientações, dentro de contextos, influências e jogos de poder, interpelados por questões microescolares e macrocontextuais (MAINARDES, 2006). Dentro do que, a arena da política educacional docente é, pois, uma congregação, como aponta Oliveira (2004).

Ball e Mainardes (2011) apresentam um modelo analítico para análise de políticas, a partir da ideia de um "ciclo" formado por três contextos nucleares (1) da prática, (2) da produção; (3) de influência; em quais mais tarde agruparam outros dois campos: (4) dos resultados/efeitos e (5) da estratégia política. E que possuem cada qual peculiaridades, mas constituem diretamente relacionais e não lineares proporcionalmente e uniformemente.

Com tais artefatos, face à fase exploratória do estudo, buscamos, neste momento, a construção de categorias teóricas "chaves", para fomentar o delineio compreensivo da proposta de estudo: a política docente dentro do horizonte capitalista. De modo que, os resultados vêm indicando-nos dois motes primordiais de estudo para apreender tal fenômeno: (I) A corporificação de uma nova forma de ser do trabalho sobre o trabalhador docente; (II) As redefinições no papel do Estado pelas vias da conjugação neoliberalismo, globalização e reestruturação produtiva, para com as políticas escolar e inclusive docente.

\section{RESULTADOS e DISCUSSÃO}

Diante do momento investigativo inicial em que a pesquisa se encontra, dois pontos têm se mostrado latentes, como sendo pertinentes de estudo, para a contemplação das relações de influência do programa capitalista para com as políticas educacionais docentes. Procuramos tratar cada ponto em separado, como forma de melhor sistematização da reflexão. Porém, sem perder de vista, o objetivo de relacionar suas articulações. 
(I) A corporificação da nova forma de ser do trabalho sobre 0 trabalhador docente. Pela ascensão de uma crise de lucros na segunda metade do século XX e como forma de superação do modelo keynesiano que prevalecia como modelo societário (ANDERSON, 1995). Propagou-se uma nova lógica acumulativa, mais flexível e menos interventora socialmente, notadamente, de ordem estritamente de horizonte econômica capital. Segundo Antunes (2001) este ideologia se propaga embasando-se no lema: "pouco investimento e máximo lucro", que produtivamente se utilizou das bases acionadas pela Automobilística Toyota. No campo social se afincou um discurso desregulamentativo social (des) regulativo que se chamou de neoliberalista, pautando ideologias privatizante e antissocial, principalmente, tendo como pauta retirar as "barreiras" capitais, sobretudo, o que guardava referencia com os entraves gerados pelo Estado e das suas políticas.

A classe docente é amplamente atingida por tais movimentações macrotrabalhistas e sociais, por se congregar como classe operária que precisa vender seu trabalho para sobreviver (BOTTOMORE, 2001). Assim, ela passa a ver sobre si reflexos no campo da desmontagem de políticas e de direitos trabalhistas; combate sindicalista através de individualismo exacerbado; temas como "empreendedorismo", "cooperativismo" e "trabalho voluntário", e a apropriação da subjetividade operária, com discursos de trabalho em equipe e coletivo, tudo com vista a uma maior produtividade, e onde o trabalhador controla a si e a seus pares (ANTUNES, 1999).

Codo (1999) coordenou uma ampla pesquisa no Brasil, objetivando elencar efeitos das transformações socioprodutivas neoliberalistas sobre os trabalhadores docentes. Delatando inúmeros reflexos, pois há uma reconfiguração em direção a um novo tipo de trabalhador, proletarizado e precarizado na qualidade de seu labor, exaurido de salários e intensificado no ritmo e volume de suas funções. Produtos que no momento em que se somam à natureza do trabalho pedagógico - um serviço que não é material e diretamente produtivo enquanto bem vendável - assume grau alarmante. Porque o professor se envolve afetivamente com seu trabalho em uma escala muito maior do que qualquer outro tipo de trabalhador que é produtor material. Isso traz atravessamentos em níveis de sentimentos de sofrimento e não 
realização, que invadem o eu profissional ao pessoal docente (OLIVEIRA, 2004).

(II) As redefinições no papel do Estado para com as políticas educacionais (PERONI, 2010), onde se incluem os docentes, através do neoliberalismo, globalização e reestruturação produtiva capital.

Estudos das políticas educacionais vêm apontando os reflexos sobre a escola do novo molde capital flexível e neoliberal. Que se estendem ao professorado, sobretudo, no Brasil, e contexto latino-americano, como ilustra Oliveira (2004).

Ball $(2001 ; 2005)$, personifica a emergência de um paradigma de governo educacional que é centrado na competitividade de mercado, e de outro lado, descompromissado de princípios sociais. O que reflete amplamente, na forma de ser do Estado e suas políticas, onde se incluem a educação e o professor.

De acordo com Ball (2001), o ser e estar do professor são focos basilares do projeto capital neoliberal a partir da fabricação de subjetividades mercantilizáveis. Para tanto, duas tecnologias endógenas têm sido impulsionadas por meio do redimensionamento da propriedade estatal: a performatividade, que se refere a assumir a regulamentação e medição de desempenhos como parâmetros de produtividade (BALL, 2005); e uma Nova Gestão Pública (NGP, do termo inglês New Public Management) conforme um Estado gerencialista e funcional aos motes empresariais de eficiência, eficácia e competividade como critério para a prática pedagógica e qualidade educacional, e que faz, em suma, a incursão da cultura performática na alma docente (CLARKE e NEWMANN, 2012).

Segundo Hypólito, Vieira e Pizzi (2009), a ótica gerencial enfoca na responsabilização (do inglês accountability). O modelo estatal gerencialista incentiva o professor a se sentir responsabilizado e culpado por seu desempenho, medido e avaliado externamente ao seu trabalho; e incentivado a procurar formação privadamente para melhorar seu desempenho. Tudo como modo de inculcamento de que estes pontos são, antes, responsabilidades governamentais (HYPOLITO, 2011).

Para nós tem sido pertinente estudar as consequências do movimento em que a educação e os serviços públicos, onde a docência e a 
pedagogia se agrupam, confluem às leis mercado. $O$ professor ao ser exposto a este diâmetro é exposto a medidas prescritivas na realização específica de suas funções, o que não somente exaure os compromissos humanísticos pedagógicos com a evocação de um estado permanente de alienação do "eu" docente. É ainda, inclinado a práticas inautênticas e impotentes de tomos filosóficos e sociais e que se relacionam com princípios de justiça social, igualdade e democratização.

Ao cabo, observamos que estes anseios, pressupõem, essencialmente, o controle do professor, com vista à legitimação de um projeto educacional, social segundo o ideal capital. Logo, com a especificidade docente desapropriada de autonomia, criatividade e de até de caráter político e cidadão. O objetivo é a propagação, nada mais do que senão, de formas impulsionadoras da perpetuação do capital, ao passo da deturpação de modelos societários e educacionais efetivamente humanizadores. Que legitimem as necessidades do homem e da sociedade no lugar de interesses mercantis e da ótica do grande capital.

\section{CONCLUSÃO}

A pesquisa que se está concretizando sobre o exame das políticas educativo-docentes e suas influências no chão-escolar, partindo do contexto social vivido, vêm impulsionando compreensões acerca da realidade escolar brasileira.

Um dos pontos investigativos mais sobressalentes tem sido 0 tocante dos (des) compromissos socioeducacionais governante do capitalismo. Diante disso, temos nos inclinado à ratificação dos alertas sobre o papel do Estado enquanto legitimador do programa capitalista, criando vias para a indução da lógica mercantil "por dentro". Quer seja no funcionamento e na forma da provisão pública. Manifesto o qual vem sendo ecoado na forma estatal e para com suas políticas no campo educacional do Brasil por Peroni (2010) e no âmbito específico do trabalho docente escolar por Oliveira e seus colaboradores (2015).

Notadamente, o governo brasileiro com políticas consonantes aos ditames do mercado deixa de lado a dignidade humana, social e trabalhadora. 
O metabolismo capital por seu alicerce guarda estas peculiaridades, de se maximizar frente à humanização do homem e da sociedade. Temos buscado descortinar tal fenômeno porque entendemos que no momento em que esse ideário se estende à educação torna-a produto lucrável. Com a educação pública tornada um tipo de mercado educacional, os professores são redimensionados a instrumentos de formação dos perfis humano-societários mercantilizáveis augurados: produtores e consumidores servis a este modo societário. A escolarização, especialmente, desempenha papel central no fornecimento de tais perfis, sobretudo, uma vez que na fase escolar é o espaço base de formação cidadã. Inclusive, na esfera brasileira, é na escola o lugar onde passam desde a tenra infância a quase completude das massas populacionais de nosso país.

No que se refere ao professor como trabalhador e também como um ser humano, temos notado que há um conjunto de impactos acometendo-o, em face de um cenário de alta intensificação e fragmentação. Observam-se reflexos que ecoam para além do eu profissional, mas na completude do eu pessoal docente, tanto no que se refere a função do trabalho na vida humana, ou seja, quanto à santificação e reconhecimento. Mesmo porque, como apresentamos, a forma estatal vem sendo compelida a um modelo de gestão, por dentro de seu estar e estar, às leis do mercado. O que incide na forma subjetividade e íntima que constitui o professor tanto quanto profissional, como também como ser humano.

Para nós, tem ficado claro que nosso desafio não colocar o professore como vítima, e também não como culpado. É sim, entendê-lo no liame deste processo, em sentido micro-macro relacional. Cabe-nos identificar o docente como trabalhador, profissionalmente, cada vez menos amparado, e em contrapartida bem mais responsabilizado por seu trabalho.

Desafia-nos compreender: Quais são, então, os desdobramentos de um Estado que se torna incentivador de competividade e individualização no lugar da cooperação? Sobretudo, quando se colocam os anseios econômicos e produtivos na frente das necessidades humanas e sociais populacionais. Neste compasso é que é assumida a necessidade de compreender o papel do professor, sendo elemento crucial na relação de ensino-aprendizagem e que ecoa sobre a formação ideológica dos sujeitos que se quer. 


\section{REFERÊNCIAS}

ANDERSON, Perry. Balanço do Neoliberalismo. Pós-neoliberalismo: as políticas sociais e o Estado democrático. Rio de Janeiro: Paz e Terra, 1995. Disponível em: $<$ http://www.portalmodulocom.br/userfiles/BALAN\%C\%870\%20DO\%20NEOLI BERALISMO.pdf.> Acesso em: 12 fev. 2013.

ANTUNES, Ricardo. Mercado informal, empregabilidade e cooperativismo: as transformações das relações de trabalho no mundo contemporâneo. Cadernos de Psicologia Social do Trabalho, v. 2, n. 1, p. 55-72, 1999.

. Trabalho e precarização numa ordem neoliberal. A cidadania negada. São Paulo: Cortez, p.35-48, 2001.

BALL, Stephen. Diretrizes Políticas Globais e Relações Políticas Locais em Educação. Currículo sem Fronteiras, v.1, n.2, p.99-116, 2001.

- Profissionalismo, Gerencialismo e Performatividade. Cadernos de Pesquisa, v. 35, n. 126, p. 539-564, 2005.

BOTTOMORE, Tom. Dicionário do Pensamento Marxista. Rio de Janeiro: Jorge Zahar Editor, 2001.

CLARKE, John; NEWMAN, Janet. Gerencialismo. Educação e Realidade, v. 37, ํo. 2, p. 353-381, 2012.

CODO, Wanderley. Educação: carinho e trabalho. Petrópolis: Vozes, 1999.

HARVEY, David. Condição pós-moderna. São Paulo: Loyola, 2013.

HYPOLITO, Álvaro. Reorganização gerencialista da escola e trabalho docente. Educação: Teoria e Prática, v. 21, №. 38, p.1-19, 2011.

- VIEIRA, Jarbas Santos e PIZZI Laura. Reestruturação Curricular e Autointensificação do Trabalho Docente. Currículo sem Fronteiras, v.9, n.2, p.100-112, 2009.

KUENZER Acácia. Sob a Reestruturação Produtiva, Enfermeiros, Professores e Montadores de Automóveis se encontram no sofrimento do trabalho. Trabalho, Educação e Saúde, v. 2, no. 1, p. 239-265, 2004.

MAINARDES, Jefferson. A abordagem do ciclo de políticas e suas contribuições para a análise da trajetória de políticas educacionais. Atos de pesquisa em educação, v. 1, № 2, p. 94-105, 2006.

MÉSZAROS, István. Para além do Capital. São Paulo: Boitempo, 2013. 
OLIVEIRA, Dalila. Reestruturação do trabalho docente: precarização e flexibilização. Educação e Sociedade, v. 25, №. 89, p. 1127-1144, 2004.

. e colaboradores. Transformações na Organização do Processo de Trabalho Docente e o Sofrimento do Professor. Disponível em: http://www.redeestrado.org/web/5/1.php?idioma=port. Acesso em 11/03/2015.

PERONI, Vera. As redefinições na relação público/privado e as implicações para a democratização da educação. Congresso Sul-brasileiro da ANPAE, p. $1-17$, 2010. Disponível em: http://www.anpae.org.br/iberolusobrasileiro2010/cdrom/123.pdf. Acesso em $11 / 03 / 2015$. 